\title{
Effect of Gold Content on the Microstructural Evolution of SAC305 Solder Joints Under Isothermal Aging
}

\author{
MIKE POWERS, JIANBIAO PAN, JULIE SILK, \\ and PATRICK HYLAND
}

\begin{abstract}
$\mathrm{Au}$ over $\mathrm{Ni}$ on $\mathrm{Cu}$ is a widely used printed circuit board (PCB) surface finish, under bump metallization (UBM), and component lead metallization. It is generally accepted that less than 3 wt.\% $\mathrm{Au}$ in $\mathrm{Sn}-\mathrm{Pb}$ solder joints inhibits formation of detrimental intermetallic compounds (IMC). However, the critical limit for $\mathrm{Au}$ content in $\mathrm{Pb}$-free solder joints is not well established. Three surface-mount package platforms, one with a matte Sn surface finish and the others with $\mathrm{Ni} / \mathrm{Au}$ finish, were soldered to Ni/Au-finished PCB using $\mathrm{Sn}-3.0 \mathrm{Ag}$ $0.5 \mathrm{Cu}$ (SAC305) solder, in a realistic manufacturing setting. The assembled boards were divided into three groups: one without any thermal treatment, one subjected to isothermal aging at $125^{\circ} \mathrm{C}$ for 30 days, and the third group aged at $125^{\circ} \mathrm{C}$ for 56 days. Representative solder joints were cross-sectioned and analyzed using scanning electron microscopy (SEM) and energy-dispersive x-ray spectroscopy (EDX) to investigate the evolution of the solder joint morphology as a function of $\mathrm{Au}$ content and isothermal aging. It was found that, if $\mathrm{Cu}$ is available to dissolve in the solder joint, the migration of $\mathrm{AuSn}_{4}$ from the bulk to the interface as a result of thermal aging is mitigated.
\end{abstract}

Key words: $\mathrm{Pb}$-free solder, isothermal aging, $\mathrm{Ni} / \mathrm{Au}$ surface finish, $\mathrm{Au}$ content, $\mathrm{Sn}-\mathrm{Ag}-\mathrm{Cu}$, intermetallic compound

\section{INTRODUCTION}

$\mathrm{Ni} / \mathrm{Au}$ over $\mathrm{Cu}$ is a popular finish metallization for PCB, UBM, and ball grid array/chip-scale package pads. Ni can be applied to $\mathrm{Cu}$ traces and pads via an electrolytic or electroless plating process and serves as a diffusion barrier layer. Au can be deposited by electrolytic, electroless, or an immersion plating process. The function of the Au layer is to protect the $\mathrm{Ni}$ layer from oxidation and corrosion, to enhance the wettability of solder to the surface, and in some applications, to improve wire bondability. While a thicker Au layer improves wire bondability, it can also increase the possibility of Au embrittlement in the resulting solder joints. It is generally accepted that less than 3 wt.\% $\mathrm{Au}$ in $\mathrm{Sn}-\mathrm{Pb}$ solder joints will inhibit the formation of detrimental
IMCs. ${ }^{1,2}$ However, the critical limit for Au content in $\mathrm{Pb}$-free solder joints is not well established.

By now, the effect of Ni/Au on Sn-Pb solder joint reliability and the mechanism for IMC formation has been established. During the solder reflow process, $\mathrm{Au}$ on the PCB pads (and/or on component metallizations) dissolves rapidly into the bulk molten solder and forms needle-like AuSn 4 IMC. ${ }^{3}$ The $\mathrm{AuSn}_{4}$ IMC is distributed throughout the bulk solder joint after reflow, and the Ni diffusion barrier reacts with $\mathrm{Sn}$ to form a thin $\mathrm{Ni}_{3} \mathrm{Sn}_{4}$ IMC at the interface. Following thermal aging at over $100^{\circ} \mathrm{C}$ for several hundred hours, the $\mathrm{AuSn}_{4}$ migrates to the $\mathrm{Ni}$ interface and forms a continuous layer of (Au,Ni)Sn $\mathrm{Sn}_{4}$ IMC over a $\mathrm{Ni}_{3} \mathrm{Sn}_{4}$ IMC layer. ${ }^{4-6}$ The weak interface between $(\mathrm{Au}, \mathrm{Ni}) \mathrm{Sn}_{4}$ and $\mathrm{Ni}_{3} \mathrm{Sn}_{4}$ can lead to brittle failure. ${ }^{7}$ The driving force for the migration of $\mathrm{AuSn}_{4}$ is a reduction of Gibbs free energy by mixing. ${ }^{8} \mathrm{Au}$ seeks $\mathrm{Ni}$ so that the $\mathrm{AuSn}_{4}$ becomes a Ni-saturated ( $\mathrm{Au}, \mathrm{Ni}) \mathrm{Sn}_{4}$ compound. $^{9}$ 
However, if the $\mathrm{Ni}$ barrier layer is sufficiently thin, then $\mathrm{Cu}$ can diffuse through the barrier to the $(\mathrm{Au}, \mathrm{Ni}) \mathrm{Sn}_{4}$ interface. ${ }^{10}$ In this case, the $(\mathrm{Au}, \mathrm{Ni}) \mathrm{Sn}_{4}$ IMC transforms to $(\mathrm{Au}, \mathrm{Cu}, \mathrm{Ni})_{6} \mathrm{Sn}_{5} \cdot{ }^{11}$ Elimination of the brittle layer of (Au,Ni)Sn $\mathrm{Sn}_{4}$ IMC over the $\mathrm{Ni}_{3} \mathrm{Sn}_{4}$ layer mitigates crack propagation along the interface. Although a thin $\mathrm{Ni}$ diffusion barrier layer produces this benefit, in practice $\mathrm{Cu}$ diffusion and oxidation can limit PCB shelf-life and hinder solderability.

The objective of this investigation is to study the morphological effect of increasing amounts of $\mathrm{Au}$ in SAC305 Pb-free solder joints between packaged integrated circuit (IC) components and PCBs with $\mathrm{Au}$ over $\mathrm{Ni}$ finish, and the evolution of the solder joint microstructures under isothermal aging at $125^{\circ} \mathrm{C}$. An important aspect of this work is to distinguish between packaged IC platforms that employ a Ni diffusion barrier and those that do not.

\section{EXPERIMENTAL PROCEDURES}

Printed circuit assemblies (PCA) were manufactured using a standard surface-mount assembly process in a realistic production environment at Jabil Circuit, San Jose, California. The test vehicle was designed as a six-layer PCB fabricated using Nelco ${ }^{\circledR}$ N4000-12 epoxy resin with an electrolytic Au over Ni finish on the $\mathrm{Cu}$ traces and pads. The solder paste was SAC305, $217^{\circ} \mathrm{C}$ melting point, type 3 with no-clean flux and a metal content of $88 \%$ by weight. The solder paste stencil was laser-cut from electroformed $\mathrm{Ni}$ with a thickness of $0.1 \mathrm{~mm}$ and a $1: 1$ aperture-to-pad ratio. The volume, area, and height of the solder paste on each pad were measured using a Koh Young KY-3030VAL solder paste inspection system. Solder reflow was performed in a Vitronics Soltec XPM2 belt furnace under nitrogen atmosphere. The reflow temperature profile displayed a maximum heating rate of $3.2^{\circ} \mathrm{C} / \mathrm{s}$, soak time of $60 \mathrm{~s}$ to $120 \mathrm{~s}$ between $150^{\circ} \mathrm{C}$ and $217^{\circ} \mathrm{C}$, peak temperature between $235^{\circ} \mathrm{C}$ and $245^{\circ} \mathrm{C}$, time above liquidus of $60 \mathrm{~s}$ to $90 \mathrm{~s}$, and maximum cooling rate of $1^{\circ} \mathrm{C} / \mathrm{s}$ to $4^{\circ} \mathrm{C} / \mathrm{s}$. All of the resulting solder joints were inspected using a Phoenix Nanomex x-ray inspection system to verify joint integrity as-built.

Three packaging platforms, in various sizes and configurations, were soldered to PCBs using two different Au thicknesses (thick and flash). All of the packaged IC components were daisy-chained to facilitate resistance measurements. The Au thickness of the surface finish from random locations on the PCBs and component pads/leads was measured using a CMI XRX series x-ray fluorescence (XRF) system. The QFN platform is a quad flat no-lead packaging technology with a matte Sn finish over $\mathrm{Cu}$ pads (i.e., no Ni diffusion barrier). Two QFN package sizes were employed, $5 \mathrm{~mm} \times 5 \mathrm{~mm}$ and $6 \mathrm{~mm} \times 6 \mathrm{~mm}$. The TOPS platform is a $10 \mathrm{~mm} \times$ $10 \mathrm{~mm}$ no-lead package with an open-cavity epoxy laminate construction. The pad finish on the TOPS is electrolytic $\mathrm{Au}$ over $\mathrm{Ni}$. The FP platform is an open-cavity ceramic package with flat $\operatorname{Kovar}^{\circledR}$ (ASTM F-15 alloy) leads and an electrolytic Au over $\mathrm{Ni}$ finish. The FP packages have two configurations, a $6.4 \mathrm{~mm} \times 6.4 \mathrm{~mm}$ footprint with 12 leads and a $10.2 \mathrm{~mm} \times 9.7 \mathrm{~mm}$ footprint with 22 leads. Figure 1 shows photographs of the footprints for the components used in this study. The type and thickness of the metallizations on the components and boards are summarized in Table I.

Due to the variation in Au thickness and solder volume at different locations on a particular board, from board to board, and on different component leads, both the average and the range of solder joint $\mathrm{Au}$ content were calculated. It was found that the

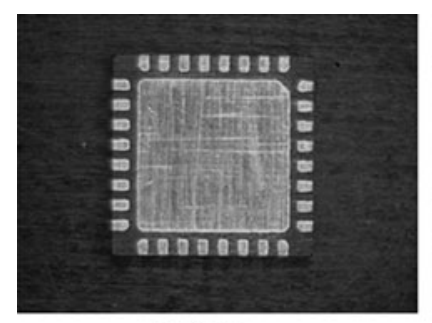

QFN5

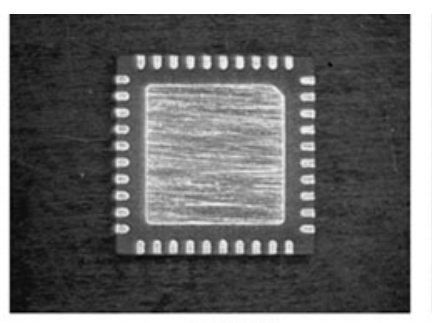

QFN6

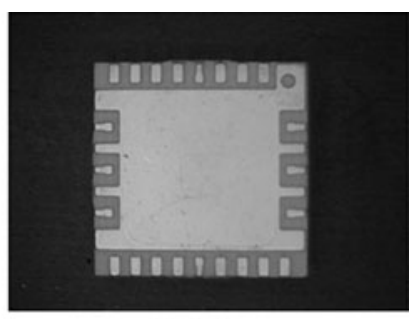

TOPS

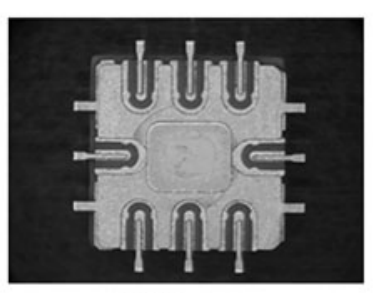

FPI

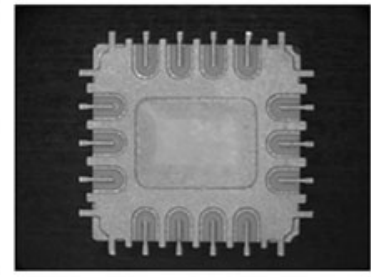

FP II

Fig. 1. Components used for PCA test vehicle. 
Table I. Metallization thickness of components and boards

\begin{tabular}{lcc}
\hline & \multicolumn{1}{c}{ Metallization } & Thickness \\
\cline { 2 - 3 } QFN & Matte Sn over Cu pads & - \\
TOPS & Ni/Au over Cu leads & \\
FP & Ni/Au over Kovar leads & $0.2 \mu \mathrm{m}$ to $0.3 \mu \mathrm{m} \mathrm{Au} \mathrm{over} 3 \mu \mathrm{m}$ to $8 \mu \mathrm{m} \mathrm{Ni}$ \\
PCB & Ni/Au over Cu traces & $1 \mu \mathrm{m}$ to $2 \mu \mathrm{m} \mathrm{Au} \mathrm{over} 1 \mu \mathrm{m}$ to $5 \mu \mathrm{m} \mathrm{Ni}$ \\
& & Flash Au: $0.08 \mu \mathrm{m}$ to $0.38 \mu \mathrm{m} \mathrm{Au} \mathrm{over} 5 \mu \mathrm{m} \mathrm{Ni}$ \\
& & Thick Au: $2 \mu \mathrm{m} \mathrm{to} 2.54 \mu \mathrm{m} \mathrm{Au} \mathrm{over} 5 \mu \mathrm{m} \mathrm{Ni}$ \\
\hline
\end{tabular}

Table II. Average and range of Au content in weight percent

\begin{tabular}{|c|c|c|c|c|c|}
\hline & QFN5 & QFN6 & TOPS & FPI & FPII \\
\hline \multicolumn{6}{|c|}{ Flash Au board } \\
\hline Average & 0.5 & 0.5 & 2.5 & 15.0 & 11.8 \\
\hline Range & $0.3-0.9$ & $0.3-0.9$ & $1.6-3.6$ & $13.0-18.0$ & $10.0-14.0$ \\
\hline \multicolumn{6}{|c|}{ Thick Au board } \\
\hline Average & 4.2 & 4.0 & 5.5 & 16.0 & 13.7 \\
\hline Range & $3.0-7.0$ & $3.0-7.0$ & $4.0-8.0$ & $14.0-19.0$ & $11.8-16.0$ \\
\hline
\end{tabular}

SAC305 solder wetted the sides and tops of Au-plated leads, which served to incrementally increase the gold content of the corresponding solder joints.

The Au content in the solder joints was calculated according to Eq. (1).

\section{RESULTS AND DISCUSSION}

The evolution of the microstructure for solder joints in this investigation is addressed in two sections, one based on a package substrate finish that does not have a Ni diffusion barrier (i.e., QFN) and

$$
\text { wt.\% } \mathrm{Au}=\frac{\mathrm{Au} \text { weight in component }+\mathrm{Au} \text { weight in PCB }}{\text { Sn-Ag-Cu weight in paste }+ \text { Au weight in component }+\mathrm{Au} \text { weight in PCB }}
$$

where the Au weight in component = (area of component lead $) \times($ Au thickness on component lead $) \times$ (density of $\mathrm{Au}$ ), the $\mathrm{Au}$ weight in $\mathrm{PCB}=($ area of pad $) \times(\mathrm{Au}$ thickness on PCB $) \times($ density of $\mathrm{Au})$, and $\mathrm{Sn}-\mathrm{Ag}-\mathrm{Cu}$ weight in paste $=($ measured solder paste volume $) \times($ metal content in volume $) \times($ density of SAC305). The average and range of Au content in solder joints associated with the various surface-mount package platforms are summarized in Table II. The $\mathrm{Au}$ content between these three package platforms on boards with thick or flash $\mathrm{Au}$ electroplating varies significantly.

After assembly, one flash Au board and one thick $\mathrm{Au}$ board were randomly selected for cross-sectioning and SEM/EDX analysis. This is the control group, since the PCAs did not receive any thermal aging. One group of boards was subjected to isothermal aging at $125^{\circ} \mathrm{C}$ for 30 days, and another group for 56 days. After isothermal aging, one flash $\mathrm{Au}$ board and one thick Au board were randomly selected for cross-sectioning and SEM/EDX analysis. The SEM used in this study was a JEOL JSM6390 equipped with a Thermo Scientific 6733A EDX. the other that includes a $\mathrm{Ni}$ barrier layer in the substrate finish. In both cases, the isothermal aging times are compared as a function of relative $\mathrm{Au}$ content in the solder joints.

\section{Cu/Sn-solder-Au/Ni/Cu System ( $<1$ wt.\% Au)}

An SEM micrograph of an as-built solder joint between a QFN component and a board with a flash $\mathrm{Au}$ finish is shown in Fig. 2. The Au content in the solder joint is about $0.9 \%$ by weight. The $\mathrm{Cu}$ lead of the component has a matte Sn finish. The board finish is $\mathrm{Ni} / \mathrm{Au}$. Figure 2 demonstrates that the interfacial IMC on both the component (top of micrograph) and board (bottom of micrograph) sides of the joint is $(\mathrm{Cu}, \mathrm{Ni})_{6} \mathrm{Sn}_{5}$, although the relative weight percentages of $\mathrm{Cu}$ and $\mathrm{Ni}$ differ. The $\mathrm{Cu}$ concentration is higher and the $\mathrm{Ni}$ concentration is lower at the component interface, as would be expected (i.e., QFN has no Ni diffusion barrier). The plethora of small nodular IMCs in the bulk solder is $(\mathrm{Au}, \mathrm{Cu}) \mathrm{Sn}_{4}$. Note that the figure annotation $35 \mathrm{Cu} 2-$ Ni63Sn means 35 wt. $\% \mathrm{Cu}, 2$ wt. $\% \mathrm{Ni}$, and 63 wt.\% $\mathrm{Sn}$, as determined by EDX. It is interesting to note 


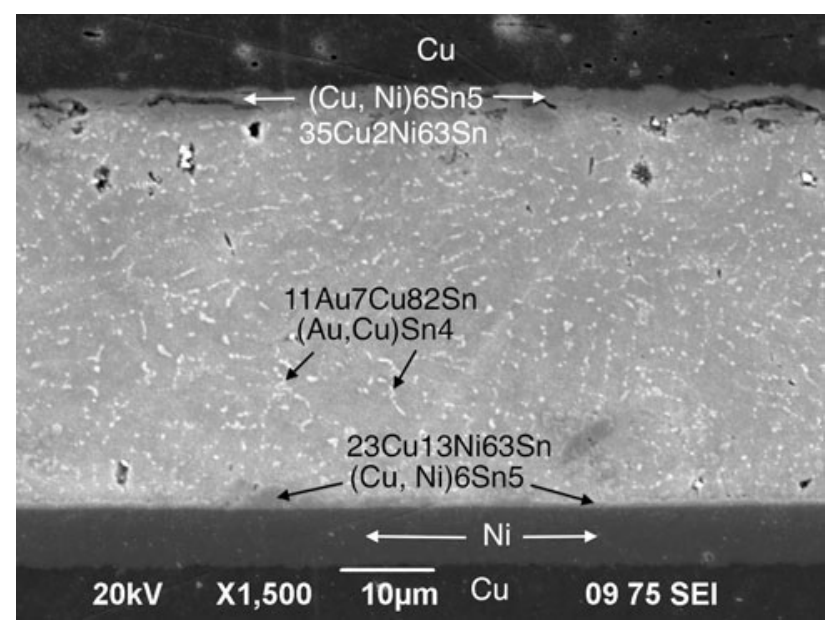

Fig. 2. SEM micrograph of an as-built solder joint between a QFN component and a board with flash Au finish. The Au content is about 0.9 wt. \%.

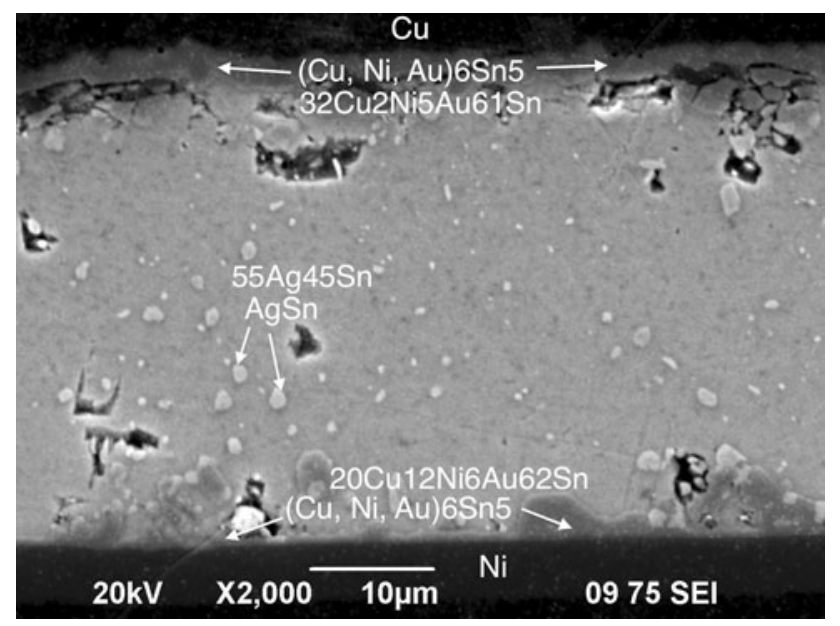

Fig. 3. SEM micrograph of an aged solder joint between a QFN component and a board with flash Au finish. The Au content is about 0.6 wt. \%. The sample was aged at $125^{\circ} \mathrm{C}$ for 30 days.

that the interfacial IMC is not $\mathrm{Ni}_{3} \mathrm{Sn}_{4}$, as typically reported for the case of $\mathrm{Sn}-\mathrm{Pb}$ solder without added Cu. ${ }^{12,13}$ The $(\mathrm{Cu}, \mathrm{Ni})_{6} \mathrm{Sn}_{5}$ IMC is consistent with that reported for the $\mathrm{Sn}-\mathrm{Ag}$-Cu case. ${ }^{14,15}$

Following isothermal aging at $125^{\circ} \mathrm{C}$ for 30 days, the microstructure of an aged solder joint with low $\mathrm{Au}$ content is shown in Fig. 3. The IMC at both the component and board interfaces is $(\mathrm{Cu}, \mathrm{Ni}, \mathrm{Au})_{6} \mathrm{Sn}_{5}$. The IMC in the bulk solder joint is AgSn, which is not consistent with the $\mathrm{Ag}_{3}$ Sn typically reported by others. ${ }^{13,16}$ This could be the result of the EDX detecting Sn outside the window, due to the small size of the IMCs analyzed (about $1 \mu \mathrm{m}$ to $2 \mu \mathrm{m}$ ). Figure 3 clearly shows that, after thermal aging, $\mathrm{Au}$ in the bulk solder of the as-built sample diffused to the interfaces, forming $(\mathrm{Cu}, \mathrm{Ni}, \mathrm{Au})_{6} \mathrm{Sn}_{5}$. It is noteworthy that $\mathrm{AuSn}_{4}$ was not observed at the interfaces or in the bulk solder after aging. This is probably due to the low Au content ( $<1 \mathrm{wt} . \%)$ in the

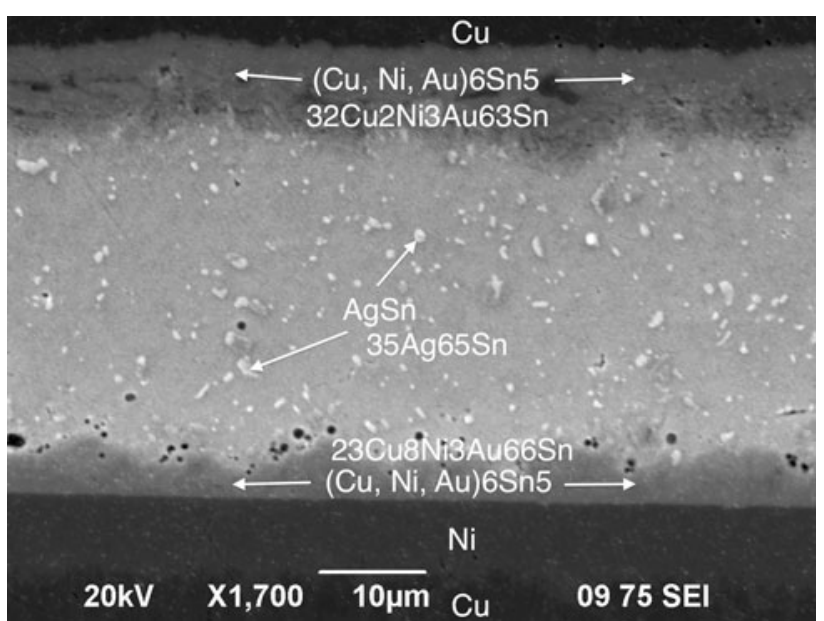

Fig. 4. SEM micrograph of an aged solder joint between a QFN component and a board with flash Au finish. The Au content is about 0.6 wt. \%. The sample was aged at $125^{\circ} \mathrm{C}$ for 56 days.

solder joint. After aging for 56 days, no significant changes were observed in the IMC composition compared with the sample aged for 30 days, as shown in Fig. 4. However, the mean IMC thickness increased from $2.4 \mu \mathrm{m}$ after reflow to $4.7 \mu \mathrm{m}$ after 30 days aging and $6.1 \mu \mathrm{m}$ after 56 days aging at the component interface. At the board interface, the mean IMC thickness increased from $1.6 \mu \mathrm{m}$ after reflow to $3.0 \mu \mathrm{m}$ after 30 days aging and $7.1 \mu \mathrm{m}$ after 56 days aging.

\section{Cu/Sn-Solder-Au/Ni/Cu System (3 wt.\% to 7 wt.\% Au)}

An SEM micrograph of an as-built solder joint between a QFN component and a board with thick $\mathrm{Au}$ finish is shown in Fig. 5. The Au content in the solder joint is about $6.3 \mathrm{wt} . \%$. The IMCs in the bulk solder joint consist of large plate-like $\mathrm{AuSn}_{4}$ and small nodular AgSn. The IMCs at the interface near the component and board side are $(\mathrm{Cu}, \mathrm{Ni}, \mathrm{Au})_{6} \mathrm{Sn}_{5}$, although the $\mathrm{Cu}$ concentration is higher on the component side and the $\mathrm{Ni}$ concentration is higher on the board side. Compared with the as-built samples with $<1$ wt.\% Au, as-built solder joints in this group manifested $\mathrm{AuSn}_{4}$ in the bulk solder as well as Au in the interfacial IMCs. It is important to note that the $(\mathrm{Cu}, \mathrm{Ni}, \mathrm{Au})_{6} \mathrm{Sn}_{5}$ IMC was identified in some samples while $(\mathrm{Cu}, \mathrm{Ni}, \mathrm{Au}) \mathrm{Sn}$ IMC was identified in other samples.

After thermal aging at $125^{\circ} \mathrm{C}$ for 30 days, the IMC at the interface near both the component and board sides was $(\mathrm{Cu}, \mathrm{Ni}, \mathrm{Au})_{6} \mathrm{Sn}_{5}$, but the weight percentages of $\mathrm{Cu}$ and $\mathrm{Ni}$ were not identical (Fig. 6). It is clear that small $\mathrm{AuSn}_{4}$ plates in the bulk solder of the as-built sample coalesced into larger $\mathrm{AuSn}_{4}$ IMC as a result of aging. The driving force for this coarsening behavior is the energy reduction associated with a lower surface-area-to-volume ratio. After thermal aging for 56 days the composition of 


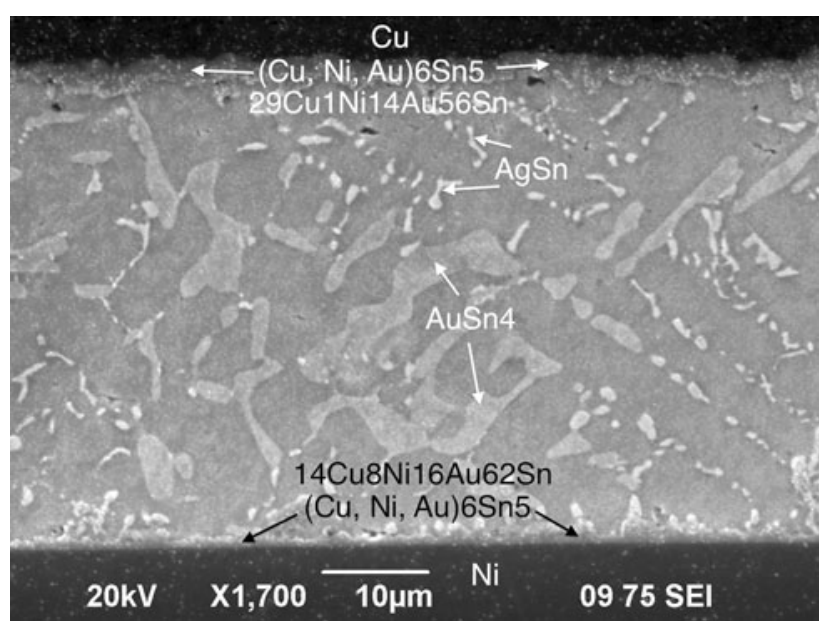

Fig. 5. SEM micrograph of an as-built solder joint between a QFN component and a board with thick Au finish. The Au content is about 6.3 wt.\%.

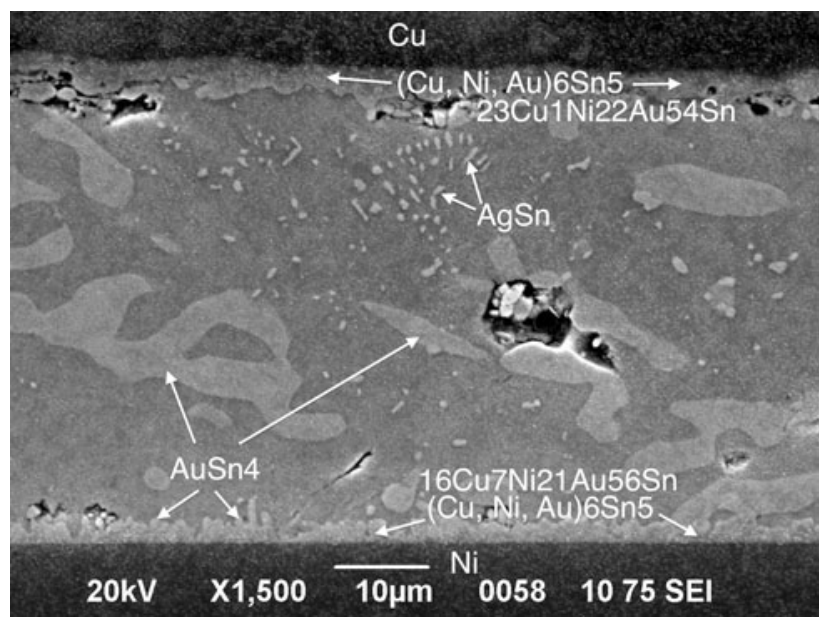

Fig. 6. SEM micrograph of an aged solder joint between a QFN component and a board with thick Au finish. The Au content is about 5.6 wt. \%. The sample was aged at $125^{\circ} \mathrm{C}$ for 30 days.

the IMCs was essentially the same, as shown in Fig. 7. However, the mean IMC thickness at the interfaces increased from $2.3 \mu \mathrm{m}$ after reflow to $3.5 \mu \mathrm{m}$ after 30 days aging and $4.8 \mu \mathrm{m}$ after 56 days aging at the component interface, while at the board interface it increased from $1.8 \mu \mathrm{m}$ after reflow to $2.8 \mu \mathrm{m}$ after 30 days aging and $5.9 \mu \mathrm{m}$ after 56 days aging. It should be pointed out that $(\mathrm{Au}, \mathrm{Ni}) \mathrm{Sn}_{4}$ over $\mathrm{Ni}_{3} \mathrm{Sn}_{4}$ was not observed after thermal aging, as commonly occurs in the $\mathrm{Sn}-\mathrm{Pb}$ case. This result is consistent with the conclusion of Ho et al. ${ }^{7}$ that the presence of sufficient $\mathrm{Cu}$ in the melt precludes redeposition of the interfacial $(\mathrm{Au}, \mathrm{Ni}) \mathrm{Sn}_{4} \mathrm{IMC}$ layer during thermal aging.

\section{$\mathrm{Cu} / \mathbf{N i} / \mathbf{A u}-\mathrm{Solder}-\mathbf{A u} / \mathbf{N i} / \mathbf{C u}$ System (2 wt.\% to 3 wt.\% Au)}

An SEM micrograph of an as-built solder joint between a TOPS component and a board with flash

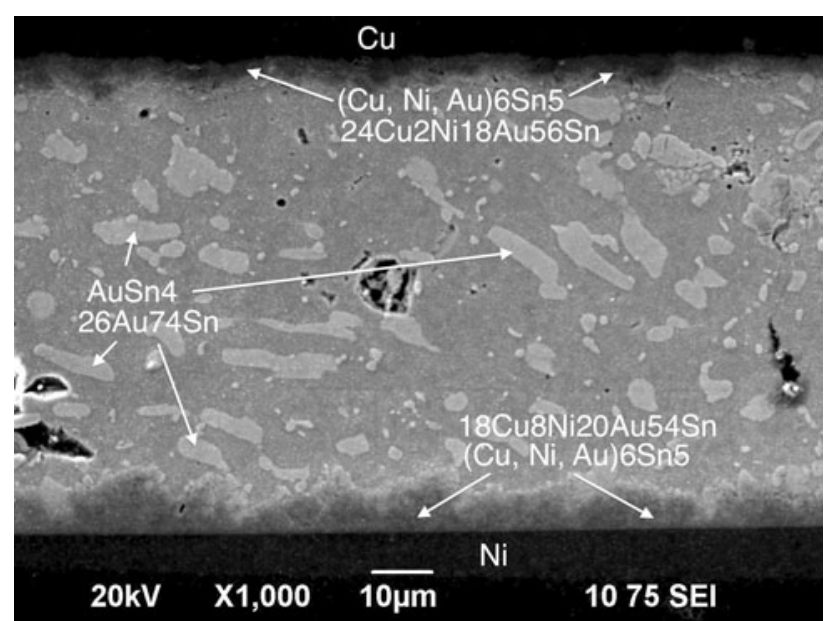

Fig. 7. SEM micrograph of an aged solder joint between a QFN component and a board with thick Au finish. The Au content is about 5.6 wt.\%. The sample was aged at $125^{\circ} \mathrm{C}$ for 56 days.

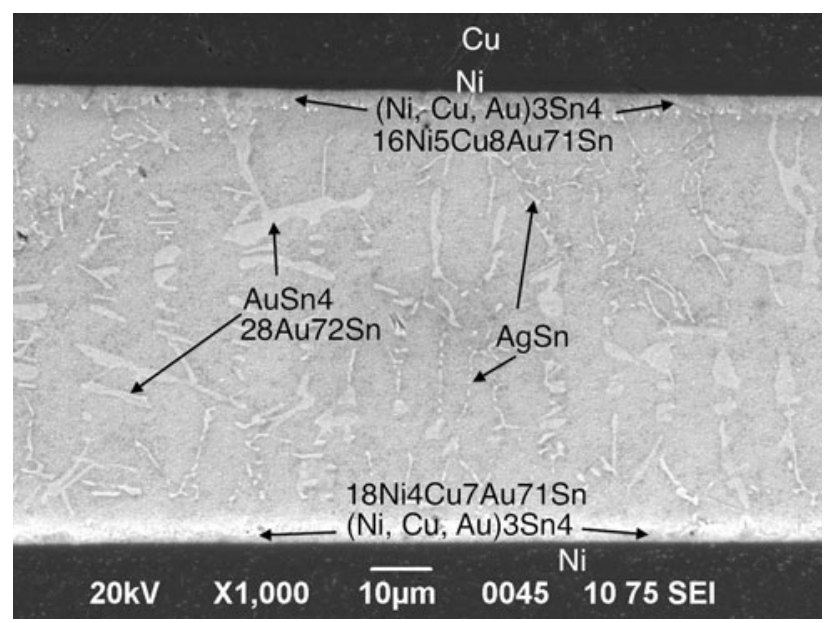

Fig. 8. SEM micrograph of an as-built solder joint between a TOPS component and a board with flash Au finish. The Au content is about 3.0 wt. \%.

Au finish is shown in Fig. 8. The Au content in the solder joint is about $3.0 \mathrm{wt} . \%$. The metallization on the $\mathrm{Cu}$ leads, as well as the PCB finish, is Au over Ni. The IMC at both the component and board interfaces is $(\mathrm{Ni}, \mathrm{Cu}, \mathrm{Au})_{3} \mathrm{Sn}_{4}$. The IMC observed in the bulk solder consists of $\mathrm{AuSn}_{4}$ and AgSn.

An SEM micrograph of a solder joint aged for 30 days is shown in Fig. 9. There are clearly two layers of IMC at the interface near the component and board side of the solder joint. The IMC adjacent to the $\mathrm{Ni}$ layer is $(\mathrm{Ni}, \mathrm{Cu}, \mathrm{Au})_{3} \mathrm{Sn}_{4}$, while the IMC near the bulk solder side is $(\mathrm{Au}, \mathrm{Ni}) \mathrm{Sn}_{4}$. The IMCs in the bulk solder are plate-like (Au,Ni) $\mathrm{Sn}_{4}$ and small nodules of AgSn. It appears that the small $\mathrm{AuSn}_{4}$ IMCs in the bulk solder of the as-built sample coalesced into larger (Au,Ni)Sn $\mathrm{Sn}_{4} \mathrm{IMCs}$ as a result of thermal aging. Following thermal aging for 56 days, no significant change in IMC composition was observed, except that the mean thickness of interfacial 


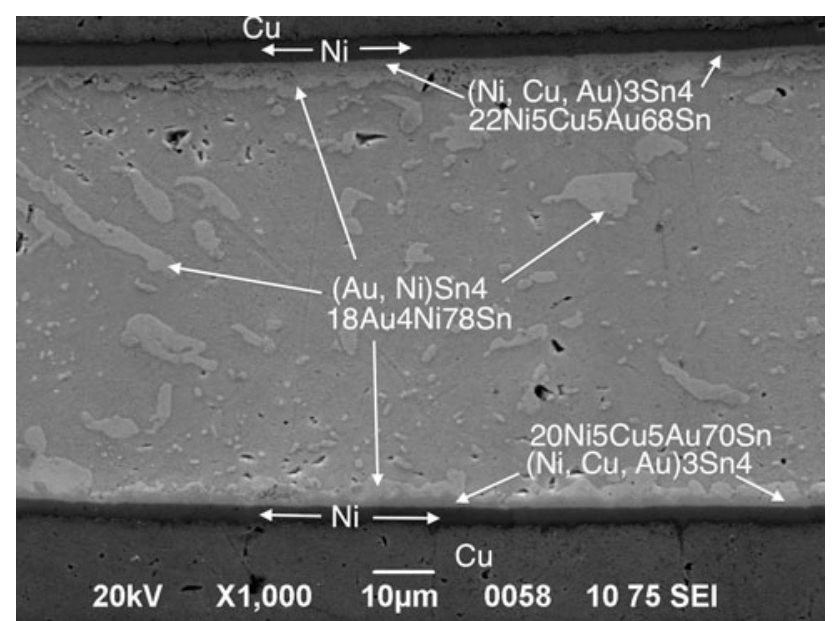

Fig. 9. SEM micrograph of an aged solder joint between a TOPS component and a board with flash Au finish. The Au content is about 2.4 wt. $\%$. The sample was aged at $125^{\circ} \mathrm{C}$ for 30 days.

IMC layers increased from $2.6 \mu \mathrm{m}$ after reflow to $4.5 \mu \mathrm{m}$ after 30 days aging and about $7 \mu \mathrm{m}$ after 56 days aging, at both interfaces.

\section{$\mathrm{Cu} / \mathrm{Ni} / \mathrm{Au}-\mathrm{Solder}-\mathrm{Au} / \mathrm{Ni} / \mathrm{Cu}$ System (4 wt.\% to 7 wt.\% Au)}

An SEM micrograph of an as-built solder joint between a TOPS component and a board with thick $\mathrm{Au}$ finish is shown in Fig. 10. The Au content in the solder joint is about $5.8 \%$ by weight. The IMC at the interface on the board side is $(\mathrm{Ni}, \mathrm{Cu}, \mathrm{Au})_{3} \mathrm{Sn}_{4}$ adjacent to the $\mathrm{Ni}$ layer with a layer of $(\mathrm{Au}, \mathrm{Ni}, \mathrm{Cu}) \mathrm{Sn}_{4}$ above it. It is difficult to distinguish separate IMC layers at the component side of the joint. The IMC on the component side is $(\mathrm{Ni}, \mathrm{Cu}, \mathrm{Au}) \mathrm{Sn}$, which could be a mix of $(\mathrm{Ni}, \mathrm{Cu}, \mathrm{Au})_{3} \mathrm{Sn}_{4}$ and $(\mathrm{Au}, \mathrm{Ni}, \mathrm{Cu}) \mathrm{Sn}_{4}$. The IMC in the bulk solder is plate-like $\mathrm{AuSn}_{4}$ and nodular $\mathrm{AgSn}_{2}$. As with the case of the AgSn IMC identified in previous figures, the $\mathrm{AgSn}_{2}$ here may actually be $\mathrm{Ag}_{3} \mathrm{Sn}$, as a result of the EDX detecting Sn outside the window due to the small size of the IMCs analyzed.

The microstructure after thermal aging for 30 days is shown in Fig. 11. The IMC adjacent to the $\mathrm{Ni}$ layer is $(\mathrm{Ni}, \mathrm{Cu}, \mathrm{Au}) \mathrm{Sn}$ and near the bulk solder side is $(\mathrm{Au}, \mathrm{Ni}) \mathrm{Sn}_{4}$. The mean IMC thickness grew from $1.9 \mu \mathrm{m}$ to $8.6 \mu \mathrm{m}$ compared with the as-built samples. The IMCs in the bulk solder changed from $\mathrm{AuSn}_{4}$ to $(\mathrm{Au}, \mathrm{Ni}) \mathrm{Sn}_{4}$ as a result of aging. After thermal aging for 56 days, there was no significant change in the composition of the IMCs, but the mean IMC thickness at both interfaces increased to approximately $9.5 \mu \mathrm{m}$.

\section{Kovar/Ni/Au-Solder-Au/Ni/Cu System (>10 wt.\% Au)}

An SEM micrograph of an as-built solder joint between an FP component and a board with flash Au finish is shown in Fig. 12. XRF measurements of

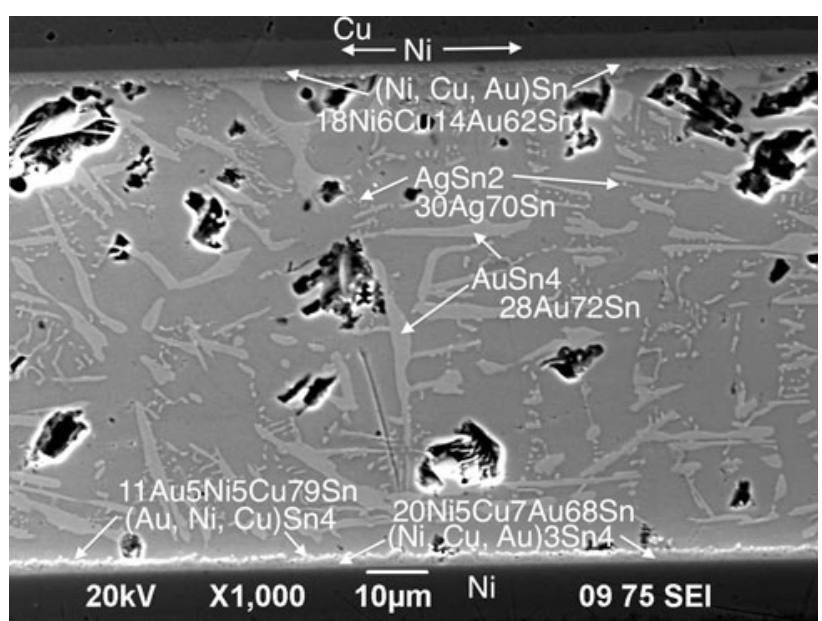

Fig. 10. SEM micrograph of an as-built solder joint between a TOPS component and a board with thick Au finish. The Au content is about 5.8 wt. \%.

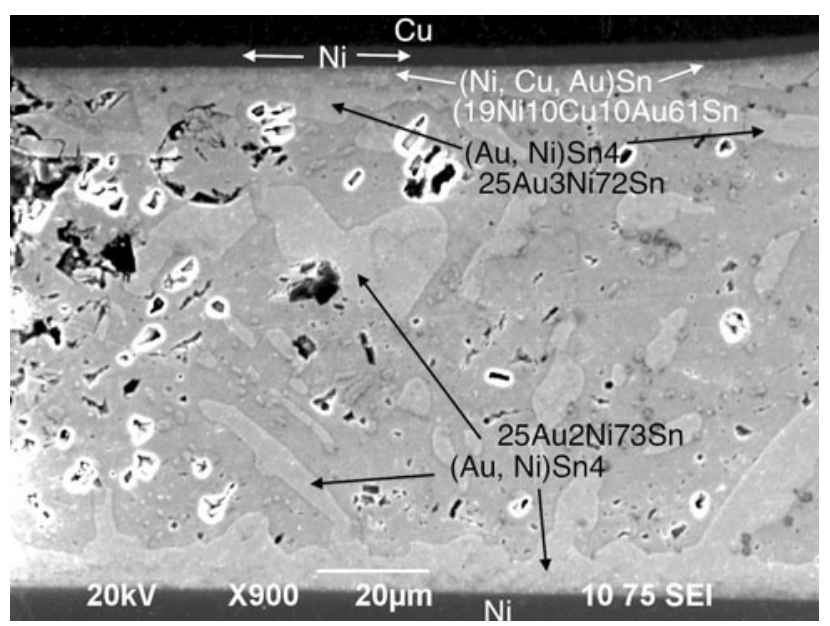

Fig. 11. SEM micrograph of an aged solder joint between a TOPS component and a board with thick Au finish. The Au content is about 7.1 wt. \%. The sample was aged at $125^{\circ} \mathrm{C}$ for 30 days.

the $\mathrm{Au}$ plating on the leads of these components revealed that the $\mathrm{Au}$ thickness was significantly higher compared with the other component platforms $(1 \mu \mathrm{m}$ to $2 \mu \mathrm{m})$. As a result, the Au content in the solder joint is about $14.4 \mathrm{wt} . \%$ and the entire joint is dominated by $(\mathrm{Au}, \mathrm{Ni}) \mathrm{Sn}_{4}$. After thermal aging for up to 56 days, there was no significant change in the composition or morphology of the IMC.

An as-built solder joint between an FP component and a board with thick Au finish is shown in Fig. 13. The Au content in this solder joint is about $15 \mathrm{wt} . \%$, and it is clear that $(\mathrm{Au}, \mathrm{Ni}) \mathrm{Sn}_{4}$ dominates the entire joint. The fracture in the solder joint was discovered immediately after assembly. The resistance measurements on the daisy-chained solder joints confirmed that opens occurred on many FP components mounted on thick Au boards. The reliability of such solder joints is very poor, as reported in other 


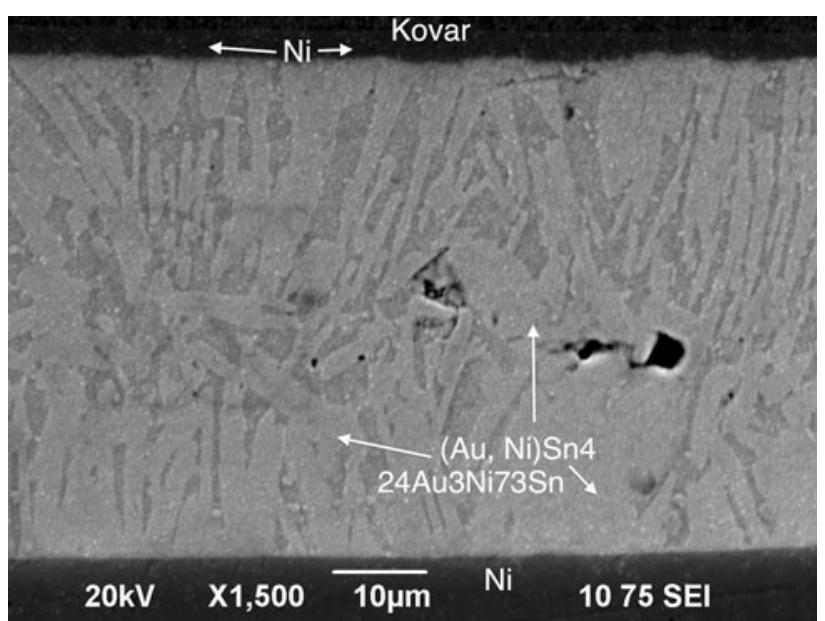

Fig. 12. SEM micrograph of an as-built solder joint between an FP component and a board with flash Au finish. The Au content is about 14.4 wt.\%.

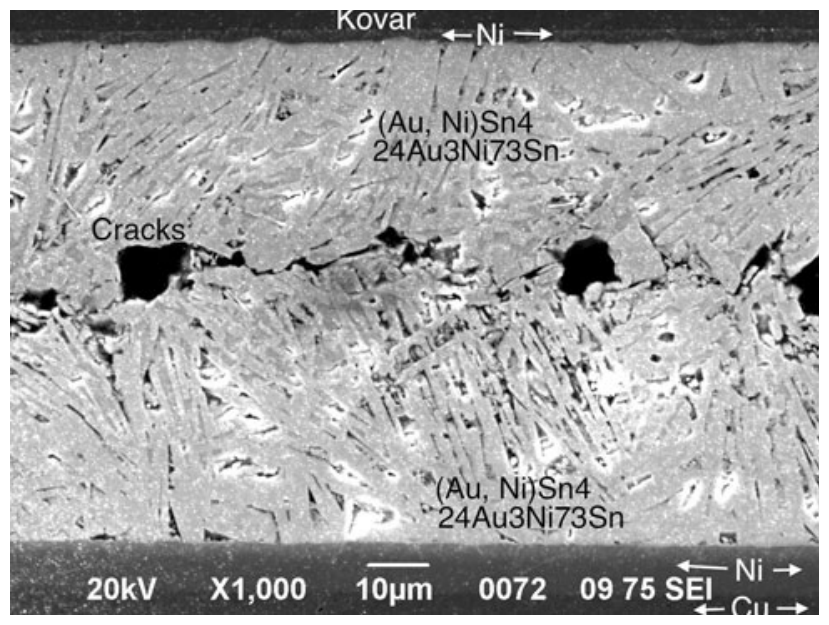

Fig. 13. SEM micrograph of an as-built solder joint between an FP component and a board with thick Au finish. The Au content is about 15 wt. \%.

publications by this group. ${ }^{17,18}$ After thermal aging for up to 56 days, no major change in the IMCs was observed, except that the cracks in the solder joints grew larger (Fig. 14). With reference to Fig. 14, the $\mathrm{Ag}_{3} \mathrm{Sn}$ IMC is identified in the bulk of the aged solder joint. This lends credence to the possibility that the AgSn and $\mathrm{AgSn}_{2}$ IMCs identified in previous figures are actually $\mathrm{Ag}_{3} \mathrm{Sn}$.

\section{CONCLUSIONS}

Packaged IC components were soldered to PCBs with a Ni/Au finish using SAC305 Pb-free solder in a "real" manufacturing environment. Some of the resulting PCAs were isothermally aged at $125^{\circ} \mathrm{C}$ for 30 days or 56 days, and the evolution of the resulting morphologies was investigated using SEM/EDX. From the experimental results obtained, the following conclusions can be drawn:

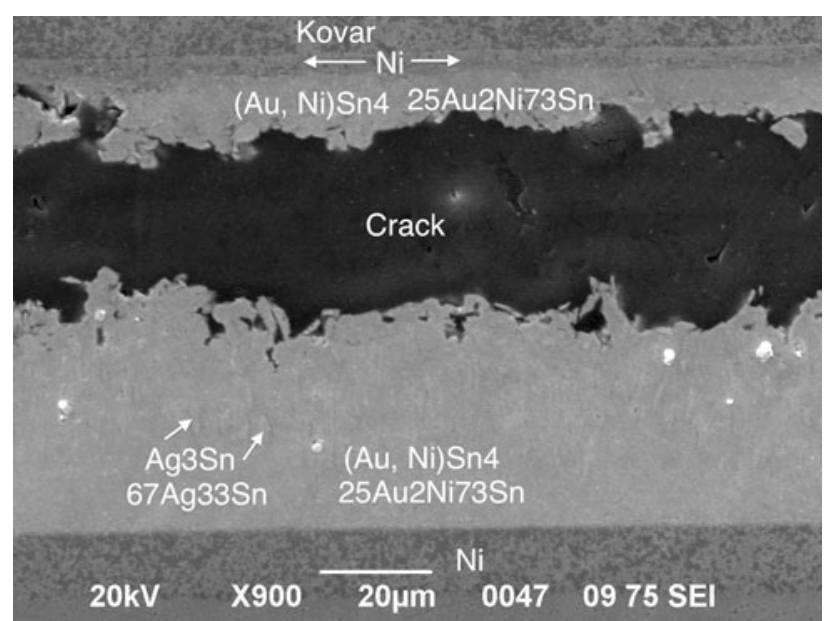

Fig. 14. SEM micrograph of a solder joint between an FP component and a board with thick Au finish. The Au content is about 15.8 wt. \%. The sample was aged at $125^{\circ} \mathrm{C}$ for 30 days.

- $\leftarrow$ When the Au content is less than 1 wt.\%, $\mathrm{AuSn}_{4}$ IMCs are not observed in the solder joint either before or after thermal aging.

- When $\mathrm{Cu}$ from the component is available to dissolve in the solder joint, the resulting interfacial IMCs are dominated by $\mathrm{Cu}$ and $\mathrm{Sn}$. The primary interfacial IMC observed is $(\mathrm{Cu}, \mathrm{Ni})_{6} \mathrm{Sn}_{5}$ or $(\mathrm{Cu}, \mathrm{Ni}, \mathrm{Au})_{6} \mathrm{Sn}_{5}$.

- If $\mathrm{Cu}$ is available to dissolve in the solder joint, $(\mathrm{Au}, \mathrm{Ni}) \mathrm{Sn}_{4}$ does not redeposit at the interface as a result of thermal aging.

- If Ni barrier layers are present on both the board and component sides of the interface, $\mathrm{Cu}$ diffusion from the substrate is mitigated and only the $\mathrm{Cu}$ from the $\mathrm{Sn}-\mathrm{Ag}-\mathrm{Cu}$ solder is available to the joint. In this case, the interfacial IMCs are dominated by $\mathrm{Ni}$ and $\mathrm{Sn}$. The primary interfacial IMC observed is $(\mathrm{Ni}, \mathrm{Cu})_{3} \mathrm{Sn}_{4}$ or $(\mathrm{Ni}, \mathrm{Cu}, \mathrm{Au})_{3} \mathrm{Sn}_{4}$.

- If Ni layers are present on both the board and component sides of the interface, availability of $\mathrm{Cu}$ in the joint is limited and $(\mathrm{Au}, \mathrm{Ni}) \mathrm{Sn}_{4}$ migrates to the interfacial IMC layer as a result of thermal aging.

- 4 In cases where the Au content is high enough to drive formation of $\mathrm{AuSn}_{4}$ in as-built solder joints, thermal aging drives the coalescence of small $\mathrm{AuSn}_{4}$ plates in the bulk solder to form larger $\mathrm{AuSn}_{4}$ IMCs, in order to decrease the surfacearea-to-volume ratio.

- 4 If the Au content is over 10 wt.\%, the entire solder joint is dominated by the brittle $(\mathrm{Au}, \mathrm{Ni}) \mathrm{Sn}_{4} \mathrm{IMC}$. Future work will study the impact of multiple reflow cycles on IMC thickness and the kinetics of IMC formation, as well as the formation of voids in the bulk solder joint.

\section{ACKNOWLEDGEMENTS}

J.P. is grateful to Agilent for funding this project during his sabbatical leave. The authors want to thank Sundar Sethuraman of Jabil for assembling 
the PCAs and Prof. Richard Savage at Cal Poly for assistance in SEM analysis.

\section{REFERENCES}

1. J. Glazer, P.A. Kramer, and J.W. Morris Jr., Circuit World 18, 41 (1992).

2. Z. Mei, Lead-Free Solder Interconnect Reliability, ed. D. Shangguan (Materials Park: ASM International, 2005), p. 29.

3. C.E. Ho, Y.M. Chen, and C.R. Kao, J. Electron. Mater. 28, 1231 (1999).

4. P.G. Kim and K.N. Tu, J. Appl. Phys. 80, 3822 (1996).

5. H.G. Song, J.P. Ahn, A.M. Minor, and J.W. Morris Jr., J. Electron. Mater. 30, 409 (2001).

6. A.M. Minor and J.W. Morris Jr., Metall. Mater. Trans. 31A, $798(2000)$

7. C.E. Ho, L.C. Shiau, and C.R. Kao, J. Electron. Mater. 31, 1264 (2002)

8. C.E. Ho, W.T. Chen, and C.R. Kao, J. Electron. Mater. 30, 379 (2001).

9. C.E. Ho, R. Zheng, G.L. Luo, A.H. Lin, and C.R. Kao, J. Electron. Mater. 29, 1175 (2000).
10. M.O. Alam, Y.C. Chan, and K.N. Tu, J. Mater. Res. 19, 1303 (2004).

11. X. Huang, S.W. Ricky Lee, M. Li, and W.T. Chen, IEEE Trans. Electron. Packag. Manuf. 31, 185 (2008).

12. M.O. Alam, B.Y. Wu, Y.C. Chan, and L. Rufer, IEEE Trans. Dev. Mater. Reliab. 6, 421 (2006).

13. C.W. Chang, C.E. Ho, S.C. Yang, and C.R. Kao, J. Electron. Mater. 35, 1948 (2006).

14. Y.L. Lin, W.C. Luo, Y.H. Lin, C.E. Ho, and C.R. Kao, J. Electron. Mater. 33, 1092 (2004).

15. D.F. Susan, P.T. Vianco, J.A. Rejent, J.J. Martin, and P.F. Hlava, Brazing and Soldering: Proceedings of the 3rd International Brazing and Soldering Conference, ed. J.J. Stephens and K. S. Weil (Materials Park, ASM International, 2006), pp. 26-31.

16. L.C. Shiau, C.E. Ho, and C.R. Kao, Solder. Surf. Mt. Technol. 14, 25 (2002).

17. J. Pan, J. Silk, M. Powers, and P. Hyland, IPC APEX EXPO Technical Conference 2011, Vol. 2 (Bannockburn: IPC, 2011), p. 1214.

18. J. Pan, J. Silk, M. Powers, and P. Hyland, IEEE Trans. Compon. Packag. Manuf. Technol. accepted for publication, 2011. 